Dublin, Ireland

\title{
University students' beliefs about language learning (BALL): Can the language used for medium of instruction impact BALL?
}

\author{
Güliz Turgut Dost \\ Aydin Adnan Menderes University
}

\begin{abstract}
Language learners' beliefs about language learning (BALL) have been investigated for over two decades through the "Language Learning Beliefs Inventory (BALLI)" developed by Horwitz $(1985 ; 1988)$. In this presentation, the results of a study comparing a total of 329 university students' BALL who varied in terms of their fields study and the language used for medium of instruction (MoI) will be presented. Participants were university students in engineering (108), medical (170) and English language teaching (ELT) (51) departments. The medical school students' MoI was Turkish. However, due to the Latin rooted medical terminology, they were already familiar with many English terminologies and had to use them as part of their job. The engineering school students' MoI was English. In order to complete their education successfully, they had to have good knowledge and use of English. The MoI in the ELT department was English. Students in engineering and ELT department had to receive a one-year compulsory English preparation education. A Kruskal-Wallis H test $(\mathrm{p}<.05)$ as well as Mann-Whitney $\mathrm{U}$ was conducted to make an overall as well as pair-wise analysis among three groups. The overall results indicate significant differences among all participant groups. Follow-up test results indicate that while the most significant differences are observed among medical and ELT students, the least difference is observed among engineering and ELT students. These results can be interpreted as students who use English as a medium of instruction, despite some minor differences, have mainly similar beliefs about language learning.
\end{abstract}

Keywords: tertiary education; beliefs about language learning; English as a foreign language; medium of instruction; quantitative research 